\title{
The first African Marine Mammal Colloquium, South Africa, May
} 2010

\author{
SH Elwen ${ }^{1}$, M Thornton ${ }^{1}$, SP Kirkman ${ }^{2,3}$, PA Pistorius ${ }^{4}$, CR Weir ${ }^{5,6}$ \\ ${ }^{1}$ Mammal Research Institute, Department of Zoology and Entomology, University of Pretoria, Based \\ at: Iziko South African Museum, 25 Queen Victoria St, Cape Town, 8000 South Africa \\ ${ }^{2}$ Oceans and Coasts, Department of Environmental Affairs, Private Bag X2, Roggebaai 8012, South \\ Africa \\ ${ }^{3}$ Animal Demography Unit, Department of Zoology, University of Cape Town, Cape Town 7701, South \\ Africa \\ ${ }^{4}$ Department of Zoology, Nelson Mandela Metropolitan University, South Campus, Port Elizabeth \\ 6031, South Africa \\ ${ }^{5}$ Ketos Ecology, 4 Compton Road, West Charleton, Kingsbridge, Devon TQ7 2BP, UK \\ ${ }^{6}$ University of Aberdeen, Zoology Building, School of Biological Sciences, Tillydrone Avenue, \\ Aberdeen, $A B 242 T Z$, $U K$
}

\section{Abstract}

The African Marine Mammal Colloquium (AMMC) was initiated to provide a platform for increased collaboration and communication between researchers working on marine mammals in and around Africa. The first meeting of the AMMC was held at Kleinbaai, South Africa, in May 2010. Talks were presented by each of the 48 participants and several discussion groups were held. Several countries were represented at the first $\mathrm{AMMC}$ but most presentations and discussions were centred on the host country. The African Journal of Marine Science agreed to host a suite of papers based on presentations given at the meeting. The 13 papers that were finally accepted comprise the first special issue of the journal to be dedicated to marine mammals. Its theme, "Conservation Biology of Marine Mammals in the Southern African Subregion", reflects both the geographical area represented in these papers and their common theme.

Key words: Africa, conservation, marine mammals 


\section{Background}

Some 51 species of cetaceans, 2 sirenians and 8 pinnipeds occur within the waters of the southern African subregion (hereafter referred to as "the subregion"; Best 2007). The geographical limits of the subregion are defined following Best (2007) as extending from the equator to the Antarctic ice edge and from the central Atlantic at $20^{\circ} \mathrm{W}$ to the central Indian Ocean at $80^{\circ} \mathrm{E}$. Research on marine mammals in the subregion has a long and productive history (e.g. see reviews Bester et al. 2011; Elwen et al. 2011, Kirkman et al. 2011), particularly in South African waters. The greater part of this research has been focused on relatively few species and comparatively few areas. Nonetheless, in the past two decades, marine mammal research in the subregion, (especially on cetaceans) has expanded considerably, both geographically and in terms of research output. Due to a lack of basic ecological knowledge on the majority of species, current research is still largely centred on estimation of population numbers, movement patterns and trophic ecology of a relatively small number of species.

The above-mentioned growth in research effort at least partly reflects increased political stability in some countries (e.g. in Mozambique and Angola). Nevertheless, access to marine mammal populations within a large part of the subregion remains severely limited by political uncertainty as well as logistical and financial limitations. Restricted access to higher education has also limited the opportunities for the training of local students and scientists, whereas a lack of museums in many parts of the region has hindered the collection and cataloguing of specimens. In addition, language barriers and limited access to information (e.g. the internet, scientific journals) continues to limit the potential for coordination and execution of research projects that have multi-national relevance within the subregion. Attendance of relevant conferences and meetings, which are mostly held outside of the subregion, is also very limited by financial resources. Apart from a recent conference (the 17th Biennial) of the Society for Marine Mammalogy (SMM) held in Cape Town in 2007, representation of African-based cetacean researchers at international marine mammal conferences is generally poor. 
The African Marine Mammal Colloquium (AMMC) was initiated in an attempt to address (at least partially) some of these challenges, in providing a platform for increased collaboration and communication between existing laboratories and researchers working on all taxa of marine mammals around the continent and associated islands. The first AMMC was co-hosted by the University of Pretoria's Mammal Research Institute (MRI) and the Dyer Island Conservation Trust (DICT), at Kleinbaai in the Western Cape province of South Africa, 18-21 May 2010. The meeting consisted of discussion groups and presentations. Topics of discussion included: (1) identification of regional research and conservation priorities; (2) identification of existing data and coordination of data collection and sharing between South African research groups; (3) coordination of groups working on Indo-Pacific humpback dolphins (Sousa chinensis) in southern Africa; (4) policy on stranding response for South Africa; (5) acoustics; (6) mark-recapture population models of relevance to marine mammal studies; (7) co-ordination of photo-identification effort and sharing of data; (8) best practice guidelines for boat-based whale watching; (8) Africa's role in the Southern Ocean Research Partnership (SORP).

All participants were encouraged to present relevant marine mammal research findings or current research engagements. In total, there were 48 presentations, mostly focused on dolphins (60\%) or whales (48\%), but also on seals $(21 \%)$ and dugongs $(10 \%)$. These are summarized in Table 1 according to the geographical area associated with each presentation. More than half of the presentations $(n=28)$ were associated with South African waters, although the South-West Indian Ocean (SWIO) including Mozambique and Madagascar was also well represented with 13 presentations. All subantarctic presentations reflected work conducted at the Prince Edward Island group (South Africa). Poorly represented at the AMMC was research or researchers based in the Eastern Tropical Atlantic (ETA) and the French subantarctic islands. The types of presentations could be classified (with overlap) as relating to research findings $(n=29)$, overviews of research or educational programmes (16) and research proposals by putative postgraduate students (3). Broadly, the following themes were embraced: conservation (18), education (6), ecotourism (12) and ecology (19). With regard to the presentations of research 
findings, the principal techniques employed included photo-identification or tag recapture (19), censuses (26), molecular techniques (stable isotopes, fatty acids, pollutants, genetics) (5) and acoustics (4). No studies using biologging (satellite tags, telemetry etc) were reported on, although the technique is used in the region, especially by seal researchers (Bester et al. 2011).

Although the AMMC was limited in terms of representation across the entire subregion, it was largely considered a success by participants. Interest was high for continuing and expanding the colloquium on a biennial basis (alternating with the biennial SMM conferences, which are usually held in North America). The AMMC should serve as a platform for participants to interact with other marine mammal researchers within Africa on a regular basis and in a location that is more accessible and affordable than many international conferences.

\section{Overview of the special issue "Conservation Biology of Marine Mammals in the} Southern African Subregion"

The African Journal of Marine Science was approached by the AMMC to host a suite of papers based on presentations given at the first AMMC. The 13 papers that were finally accepted comprise the first special issue of the journal to be dedicated to marine mammals. The theme of the special issue is, "Conservation Biology of Marine Mammals in the Southern African Subregion”. The focus on the subregion was influenced by the lack of submissions associated with areas further to the north. 'Conservation biology', which has been described as "the application of science to conservation problems [through addressing] the biology of species, communities, and ecosystems that are perturbed, either directly or indirectly, by human activities or other agents" (Soule 1985) was felt to be more suitably descriptive of the body of work than mere "Conservation". Nevertheless, it is still a broad theme and this is reflected in the diversity of papers included. 
The first six research papers all concern cetaceans. Firstly, Barendse et al (2011) analyse a consolidated photographic and genotypic sighting database to address vexing questions regarding migration and residency of humpback whales Megaptera novaeangliae found off the west coast of South Africa. Findlay et al. (2011a) then take us to the east coast of South Africa. Using shore-based monitoring at Cape Vidal, Kwazulu-Natal, they assess the recovery in the numbers of migratory humpback whales in this area following historical depletion. Using data collected opportunistically during the same study, Photopoulou et al. (2011) describe the movement patterns of coastal bottlenose dolphins Tursiops aduncus in the presence of a fast-flowing, prevailing current off the coast of Cape Vidal. Penry et al. (2011) also utilize data that was mainly collected from "platforms of opportunity", this time to investigate the seasonal occurrence of Bryde's whale Balaenoptera edeni (one of the less-studied large whales in the subregion) in Plettenberg Bay on the south east coast of South Africa. Being able to estimate the number of whales present in an area from recorded call rates could be a very useful monitoring tool; Hofmeyr-Juritz and Best (2011) ask whether it is realistic in the case southern right whales Eubaelaena australis, in a study conducted at Walker Bay on the south west coast of South Africa. Meÿer et al. (2011) finish up the cetacean research papers, by assessing entanglement of whales in shark exclusion nets and other gear in South African waters, including trends in entanglement rates, impacts on populations, and management interventions.

Non-cetacean research papers that follow include just one on the dugong Dugong dugon and two on the Cape fur seal Arctocephalus pusillus. Using aerial surveys, Findlay et al. (2011b) provide an update of the status of the dugong population of Mozambique's Bazaruto Archipelago, believed to be the only viable dugong population in the subregion. Huisamen et al (2011) describe the re-colonisation of a previously extinct Cape fur seal colony at Plettenberg Bay and Hofmeyr et al. (2011) assess the efficacy of reintroducing stranded Cape fur seal pups to their natal colony in Algoa Bay, at the eastern-most extreme of the breeding range of the population.

The last four papers are review papers. Elwen et al. (2011) provide a comprehensive review of cetacean research within the subregion from the 1800 s to the present, in which they provide an overview of findings, identify knowledge gaps and propose 
Table 1. Geographical areas associated with presentations at the first AMMC.

\begin{tabular}{lc} 
Country & Number of presentations \\
\hline South Africa & 28 \\
Mozambique & 6 \\
Namibia & 3 \\
Eastern tropical Atlantic & 1 \\
Kenya & 1 \\
Tanzania & 3 \\
Mauritius/Rodrigues/Mascarenes & 2 \\
Madagascar / Comoros & 3 \\
Sub-Antarctic Islands & 2 \\
Southern Ocean & 28 \\
Other (Mediterranean) & 6 \\
Total & $\mathbf{4 8}$ \\
\hline
\end{tabular}

priorities for future research with conservation threats in mind. Kirkman et al. (2011) review research and monitoring priorities for the Cape fur seal population, taking into account historical and recent shifts in management goals. Bester et al (2011) document the history of marine mammal research at South Africa's only subantarctic territorial possession, the Prince Edward Islands, providing insights into many aspects of southern elephant seal (Mirounga leonina) and fur seal Arctocephalus spp. biology. Following from this, Pistorius et al (2011) go into greater depth to describe life history parameters, derived from a long-term mark-recapture program, in southern elephant seals at these islands. 


\section{Literature Cited}

Barendse J, Best PB, Thornton M, Elwen SHh, Rosenbaum HCc, Carvalho I, Pomilla C, Collins TJQ, Meÿer MA, Leeney RH. 2011. Transit station or destination? Attendance patterns, regional movement, and population estimate of humpback whales Megaptera novaeangliae off western South Africa based on photographic and genotypic matching. African Journal of Marine Science 32(3) Special Issue on Conservation Biology of Marine Mammals in the Southern African Subregion Eds Pillar, S, Kirkman, S, Elwen S, Pistorious PA, Thornton, M and Weir C. pg $\mathbf{X x X}$

Best PB. 2007. Whales \& Dolphins of the Southern African Subregion. Cape Town: Cambridge University Press.

Bester MN, De Bruyn PJN, Oosthuizen WC, Tosh CA, Mcintyre T, Reisinger RR, Postma M, van der Merwe DS, Wege M. 2011. The Marine Mammal Programme at the Prince Edward Islands: 38 Pears of Research. African Journal of Marine Science. African Journal of Marine Science 32(3) Special Issue on Conservation Biology of Marine Mammals in the Southern African Subregion Eds Pillar, S, Kirkman, S, Elwen S, Pistorious PA, Thornton, $M$ and Weir C. pg xxx

Elwen SH, Findlay KP, Kiszka J, Weir CR. 2011. Cetacean research in the southern African subregion: a review of previous studies and current knowledge African Journal of Marine Science. African Journal of Marine Science 32(3) Special Issue on Conservation Biology of Marine Mammals in the Southern African Subregion Eds Pillar, S, Kirkman, S, Elwen S, Pistorious PA, Thornton, M and Weir C. pg $\mathbf{X X X}$

Findlay, KP, Best PB, Meÿer MA. 2011. Migrations of humpback whales past Cape Vidal, South Africa, and an estimate of the population increase rate (1988-2002). African Journal of Marine Science 32(3) Special Issue on Conservation Biology of Marine Mammals in the Southern African Subregion Eds Pillar, S, Kirkman, S, Elwen S, Pistorious PA, Thornton, $M$ and Weir C. pg xxx

Findlay KP, Cockcroft VG, Guissamulo AT. 2011. Dugong Dugong dugon abundance and distribution in the Bazaruto Archipelago, Mozambique. African Journal of Marine Science 32(3) Special Issue on Conservation Biology of Marine Mammals in the Southern African Subregion Eds Pillar, S, Kirkman, S, Elwen S, Pistorious PA, Thornton, $M$ and Weir C. pg xxx 
Hofmeyr-Juritz, L and Best, PB 2011. Acoustic behaviour of southern right whales in relation to numbers of whales present in Walker Bay, South Africa. African Journal of Marine Science 32(3) Special Issue on Conservation Biology of Marine Mammals in the Southern African Subregion Eds Pillar, S, Kirkman, S, Elwen S, Pistorious PA, Thornton, $M$ and Weir C. pg xxx

Hofmeyr GJG, du Toit M, Kirkman SP. 2011. Early post-release survival of stranded Cape fur seal pups at Black Rocks, Algoa Bay. African Journal of Marine Science 32(3) Special Issue on Conservation Biology of Marine Mammals in the Southern African Subregion Eds Pillar, S, Kirkman, S, Elwen S, Pistorious PA, Thornton, $M$ and Weir C. pg Xxx

Huisamen J, Kirkman SP, Watson LH, Cockcroft VG, Pistorius PA. 2011. Recolonisation of the Robberg Peninsula (Plettenberg Bay, South Africa) by Cape fur seal. African Journal of Marine Science 32(3) Special Issue on Conservation Biology of Marine Mammals in the Southern African Subregion Eds Pillar, S, Kirkman, S, Elwen S, Pistorious PA, Thornton, M and Weir C. pg xxx

Kirkman SP, Oosthuizen WH, Meÿer MA, Seakamela SM, Underhill LG. 2011. Prioritising range-wide scientific monitoring of the Cape fur seal Arctocephalus pusillus pusillus in southern Africa. African Journal of Marine Science 32(3) Special Issue on Conservation Biology of Marine Mammals in the Southern African Subregion Eds Pillar, S, Kirkman, S, Elwen S, Pistorious PA, Thornton, $M$ and Weir C.pg xxx

Meÿer MA, Best PB, Anderson-Reade MD, Cliff G, Dudley SFJ, Kirkman SP. 2011 Trends and interventions in large whale entanglement along the South African coast. African Journal of Marine Science 32(3) Special Issue on Conservation Biology of Marine Mammals in the Southern African Subregion Eds Pillar, S, Kirkman, S, Elwen S, Pistorious PA, Thornton, $M$ and Weir C. pg xxx

Penry GS, Hammond PS, Cockcroft VG. 2011. Seasonal fluctuations in occurrence of inshore Bryde's whales in Plettenberg Bay, South Africa, with notes on feeding events and multi-species associations. African Journal of Marine Science 32(3) Special Issue on Conservation Biology of Marine Mammals in the Southern African Subregion Eds Pillar, S, Kirkman, S, Elwen S, Pistorious PA, Thornton, $M$ and Weir C.pg Xxx 
Photopoulou T, Best PB, Hammond PS, Findlay K. 2011. Movement patterns of bottlenose dolphins Tursiops aduncus in the presence of a fast flowing, prevailing current: shore-based observations at Cape Vidal, South Africa. African Journal of Marine Science 32(3) Special Issue on Conservation Biology of Marine Mammals in the Southern African Subregion Eds Pillar, S, Kirkman, S, Elwen S, Pistorious PA, Thornton, $M$ and Weir C. pg xxx

Pistorius PA, de Bruyn PJN, Bester MN 2011. Population dynamics of southern elephant seals: a synthesis of three decades of demographic research at Marion Island. African Journal of Marine Science 32(3) Special Issue on Conservation Biology of Marine Mammals in the Southern African Subregion Eds Pillar, S, Kirkman, $S$, Elwen S, Pistorious PA, Thornton, $M$ and Weir C. pg xxx

Soulé, M. 1985. What is conservation biology? Bioscience 35 (11): 727-734 